\title{
Peripheral and central somatosensory nerve conduction defects in Friedreich's ataxia
}

\author{
S J JONES, M BARAITSER*, AND A M HALLIDAY \\ From the Institute of Neurology, the National Hospital for Nervous Diseases, Queen Square, London
}

SUMMARY Somatosensory evoked potentials were recorded over the clavicle, cervical spine, mastoid processes and the hand area of the contralateral somatosensory cortex to median nerve stimulation in 22 cases of Friedreich's ataxia. There was a marked attenuation of the clavicular potential, but little evidence of delay in this or the major cervical component. A dispersed and delayed cortical response was therefore suggestive of slowed conduction in central pathways. The cortical response was shown to be mediated by peripheral fibres with normal conduction velocity between stimulation sites at the wrist and the elbow.

The underlying biochemical cause of sensory dysfunction in Friedreich's ataxia is unknown, although the combination of peripheral neuropathy with degenerative changes of the posterior columns is compatible with a disorder primarily affecting the dorsal root ganglia. Evidence from electrophysiological and pathological studies of the peripheral nerve is consistent with an axonal form of neuropathy, ${ }^{1-6}$ although secondary segmental demyelination has been observed in some fibres of the sural nerve at biopsy. ${ }^{\text {? }}$

In contrast to the multiplicity of peripheral nerve conduction studies there have been relatively few electrophysiological investigations of the central nervous system in this disorder, no doubt because a sufficiently powerful non-invasive technique for recording small potentials generated in the spinal cord and subcortical cerebral structures has not been available until recently. ${ }^{8-10}$ It has been reported, however, that somatosensory evoked potentials (SEPs) generated in the cerebral cortex and recorded by scalp electrodes are typically delayed and of dispersed waveform, ${ }^{11-13}$ and it has recently been observed that delayed cortical SEPs may be recorded in conjunction with cervical potentials of nearnormal latency. ${ }^{14-15}$ The present study was undertaken in order to investigate this phenomenon more fully. It was also hoped to establish whether the pattern of SEP abnormality is sufficiently characteristic for the technique to be used as an aid to early diagnosis.

Address for reprint requests: Dr SJ Jones, Division of Inherited Metabolic Diseases. Clinical Research Centre, Northwick Park Hospital.

Accepted 22 January 1980

\section{Material}

The patient group consisted of 22 cases in whom the diagnosis of Friedreich's ataxia had been made according to clinical and genetic criteria. There were 13 males and nine females, aged from nine to 57 years with a mean age of 33.5 years. A group of normal volunteers was used for comparison, consisting of 10 subjects (three male, seven female) with a mean age of 26.9 years and range $21-32$ years. In all patients except one the onset had been before the age of 20 and in all cases the mode of inheritance was compatible with an autosomal recessive transmission. All the patients had cerebellar ataxia, dysarthria, absent reflexes and "posterior column" type sensory loss in the lower limbs. The disorder had been progressive, without remission, for at least two years prior to the time at which the patients were examined and SEPs recorded. Extensor plantar reflexes, pes cavus and scoliosis were present in more than $70 \%$ of patients, and nystagmus and cadomyopathy (ECG evidence) occurred in more than $60 \%$.

\section{Methods}

The subjects were seated comfortably in an armchair, although in patients with scoliosis it was often not possible to achieve complete relaxation. A capacitor discharge stimulus with a time constant of $50 \mu \mathrm{s}$ was delivered every $510 \mathrm{~ms}$ to the median nerve at the wrist or the elbow, the intensity being adjusted so as to produce a moderate twitch of the thenar muscles. SEPs were recorded with disc 
electrodes located over the clavicles, cervical vertebrae at $\mathrm{C} 7$ and $\mathrm{C} 2$, mastoid processes and contralateral somatosensory cortex. The scalp location for the latter was $7 \mathrm{~cm}$ lateral to the midline on a line joining a point $2 \mathrm{~cm}$ posterior to the vertex with the external auditory meatus. A mid-frontal "reference" electrode (located $12 \mathrm{~cm}$ above the nasion) was used for all "active" sites except the mastoid processes, for which the somatosensory area contralateral to the stimulus was used as "reference."

The amplifier high-frequency response was better than $-3 \mathrm{~dB}$ at $5 \mathrm{kHz}$ and the time constant was $1 \mathrm{~s}$. Groups of 400 responses were summed on eight channels simultaneously with an averager epoch of $32 \mathrm{~ms}$ (eight sample points/ms) starting $3 \mathrm{~ms}$ after the stimulus pulse. If no cortical response could be identified within this period an epoch of $128 \mathrm{~ms}$ ( 2 sample points/ms) was also employed. Summated responses were stored on digital magnetic tape and further combined off-line to obtain sums consisting of up to 1600 individual responses for each patient.

\section{Results}

The potentials examined were the early negativegoing waves (N9, N13, N14) recorded from the clavicle of the stimulated arm, C7 vertebra (also C2) and mastoid processes respectively, the components being labelled according to their mean peak latencies in normal subjects, ${ }^{9}$ plus the first negative potential (N20) recorded from the scalp overlying the somatosensory cortex contralateral to the stimulated arm (Fig 1). N9, N13 and N20 are well recorded with a mid-frontal reference, aided (with the possible exception of $\mathbf{N 2 0}$ ) by the presence of positive-going potentials of similar latency at the reference location. ${ }^{9} \mathrm{~N} 14$ is frequently better defined by use of an "active" electrode on the mastoid process (see Fig 1), with the "reference" location on the post-central scalp contralateral to the stimulated arm. ${ }^{8}$ The $\mathbf{N 1 1}$ component $^{9}$ was not examined since identification may be difficult in some normal subjects and even more so in a large proportion of Friedreich's patients, due to the greater frequency of muscular artifacts. N9, N13 and $\mathrm{N14}$ were absent in at least $50 \%$ of Friedreich's cases but, when present, were measured for their baseline-topeak amplitude and peak latency, excepting N14 for which the amplitude parameter was considered of doubtful validity owing to overlap with N13. The amplitude, onset and peak latency of N20 (absent in less than $10 \%$ of cases) were also measured.

\section{SJ Male 29 years}

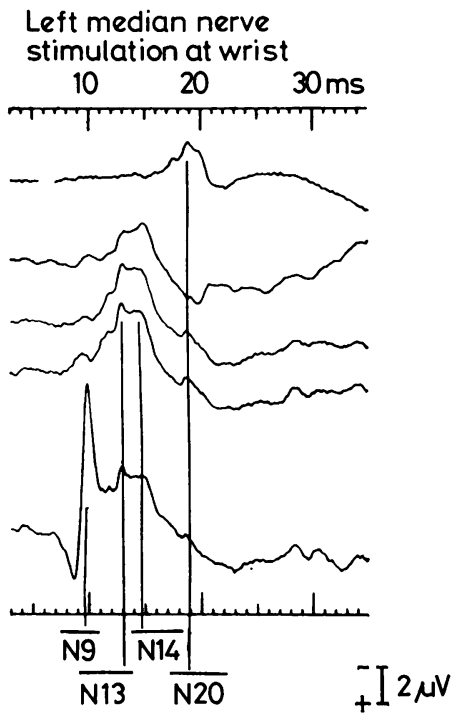

Channel 1

Left median nerve

stimulation at:-

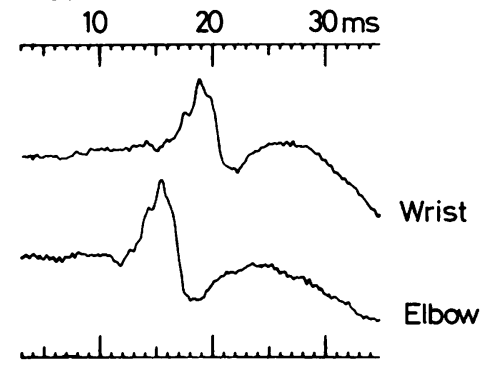

Fig 1 Short latency somatosensory evoked potentials recorded over the clavicle, cervical vertebrae, mastoid process and scalp somatosensory hand area following median nerve stimulation at wrist or elbow in a normal individual (two stimuli per second, average of $+\mathrm{I} 1 \mu \mathrm{V}$ 400 sweeps). The components studied are labelled on the left, and the difference in N2O latency between wrist and elbow stimulation is illustrated on the right. 
Table 1 Amplitude and latency parameters of short latency SEP components in normal subjects

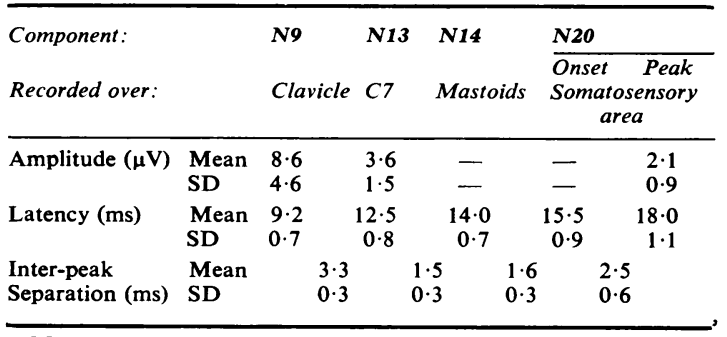

Means and standard deviations of SEP component amplitude latency and inter-peak separation in 10 healthy individuals ( 3 male, 7 female), median nerve stimulation at the wrist. For each subject the mean value for left and right arm stimulation was incorporated in the group mean.

The left and right arms were stimulated individually in all the 10 healthy controls and, since there was no marked effect of stimulus laterality on the amplitude or latency of any potential, the mean value of each parameter following left and right arm stimulation was incorporated into an overall group mean (table 1). A similar procedure (stimulation of both arms individually with an averager epoch of $32 \mathrm{~ms}$ ) was adopted for 10 of the Friedreich's patients since, although some components were judged to be unilaterally or bilaterally absent, there was again no marked difference between left and right sided stimulation in any individual or in the group as a whole (table 2). It was also considered justifiable to include five patients in whom one arm only was stimulated (two with all potentials absent) and a further seven in whom only the longer averager epoch was employed on the second arm to be studied. Where a given potential was obtained to stimulation of one arm only, for whatever reason, amplitude and latency values for this side alone were incorporated into the overall group means.

In the assessment of individual cases a potential was classified as being of prolonged latency (table 3) when its mean peak latency following stimulation at the left and right wrist exceeded the normal mean by more than 2.5 standard deviations of the control group, or when the interval separating it from the preceding potential similarly exceeded the normal range. A classification of "reduced amplitude" was made when the mean value for the left and right arm fell below the absolute minimum of the normal group (approximately $1 \cdot 1 \mu \mathrm{V}$ for each potential, although lower values for $\mathbf{N 2 0}$ amplitude have been encountered in other normal subjects) or when the potential was judged to be present for one

Table 3 Short latency SEP component classification in Friedreich's ataxia cases

\begin{tabular}{|c|c|c|c|c|c|c|}
\hline \multirow{2}{*}{\multicolumn{2}{|c|}{$\begin{array}{l}\text { Component: } \\
\text { Recorded over: }\end{array}$}} & \multirow{3}{*}{$\begin{array}{l}\text { N9 } \\
\text { Clavicle } \\
2\end{array}$} & \multirow{3}{*}{$\begin{array}{l}\text { N13 } \\
C 7 \\
5\end{array}$} & \multirow{3}{*}{$\begin{array}{l}\text { N14 } \\
\text { Mastoids } \\
-\end{array}$} & \multirow{2}{*}{\multicolumn{2}{|c|}{$\begin{array}{l}\text { N20 } \\
\begin{array}{l}\text { Onset Peak } \\
\text { Somatosensory } \\
\text { area }\end{array}\end{array}$}} \\
\hline & & & & & & \\
\hline \multirow[t]{2}{*}{ Amplitude } & $\begin{array}{l}\text { Normal in } \\
\text { (cases) }\end{array}$ & & & & - & 9 \\
\hline & Reduced & 8 & 6 & - & - & 11 \\
\hline Latency & $\begin{array}{l}\text { Normal } \\
\text { Prolonged }\end{array}$ & $\begin{array}{l}9 \\
1\end{array}$ & $\begin{array}{l}6 \\
5\end{array}$ & $\begin{array}{l}2 \\
6\end{array}$ & $\begin{array}{r}0 \\
20\end{array}$ & $\begin{array}{r}0 \\
20\end{array}$ \\
\hline \multicolumn{2}{|c|}{ Absent potential } & 12 & 11 & 14 & 2 & 2 \\
\hline
\end{tabular}

Classification of SEP components in 22 patients with Friedreich's ataxia. A given potential was judged to be reduced when the mean amplitude following stimulation of the left and right arm fell below the absolute range of the normal group (lower limit approximately $1 \cdot 1 \mu \mathrm{V}$ for each component), or when the potential was present for one arm but absent for the other. A potential was classified as being of prolonged latency when the mean latency from the left and right wrist exceeded the normal mean by more than $2 \cdot 5$ standard deviations (see table 1), or when the interval separating it from the preceding peak similarly exceeded the normal range.

Table 2 Amplitude and latency parameters of short latency SEP components in Friedreich's ataxia cases

\begin{tabular}{|c|c|c|c|c|c|c|c|c|c|}
\hline \multirow{2}{*}{$\begin{array}{l}\text { Component: } \\
\text { Recorded over: }\end{array}$} & & \multirow{2}{*}{$\begin{array}{l}\text { No } \\
\text { Clavicle }\end{array}$} & & \multirow{2}{*}{$\begin{array}{l}N 13 \\
\mathrm{C} 7\end{array}$} & & \multirow{2}{*}{$\begin{array}{l}\text { N14 } \\
\text { Mastoids }\end{array}$} & & \multicolumn{2}{|l|}{$\mathrm{N20}$} \\
\hline & & & & & & & & $\begin{array}{c}\text { Onset } \\
\text { Som }\end{array}$ & $\begin{array}{l}\text { Peak } \\
\text { rea }\end{array}$ \\
\hline Amplitude $(\mu \mathrm{V})$ & $\begin{array}{l}\text { Mean } \\
\text { SD } \\
\mathrm{N} / 22(\%) \\
\mathrm{p}<\end{array}$ & $\begin{array}{c}1 \cdot 3 \\
0.8 \\
10(45 \%) \\
0.02\end{array}$ & & $\begin{array}{c}1.4 \\
0.7 \\
11(50 \%) \\
0.02\end{array}$ & & $\begin{array}{l}- \\
- \\
-\end{array}$ & & $\begin{array}{l}- \\
- \\
-\end{array}$ & $\begin{array}{c}1.6 \\
0.6 \\
20(91 \%) \\
0.02\end{array}$ \\
\hline Latency (ms) & $\begin{array}{l}\text { Mean } \\
\text { SD } \\
\mathrm{N} / 22(\%) \\
\mathrm{p}<\end{array}$ & $\begin{array}{l}10 \cdot 6^{*} \\
4 \cdot 6 \\
10(45 \%) \\
\text { ns }\end{array}$ & & $\begin{array}{c}13.4 \\
1.5 \\
11(50 \%) \\
0.05\end{array}$ & & $\begin{array}{l}16 \cdot 4 \\
2 \cdot 0 \\
8(36 \%) \\
0.01\end{array}$ & & $\begin{array}{c}21 \cdot 7 \\
3 \cdot 8 \\
20(91 \%) \\
0.01\end{array}$ & $\begin{array}{c}32.4 \\
6.3 \\
20(91 \%) \\
0.01\end{array}$ \\
\hline $\begin{array}{l}\text { Inter-peak } \\
\text { Separation (ms) }\end{array}$ & $\begin{array}{l}\text { Mean } \\
\text { SD } \\
\mathrm{N} / 22(\%) \\
\mathrm{p}<\end{array}$ & & $\begin{array}{l}4 \cdot 4 \\
1 \cdot 1 \\
9(41 \%) \\
0 \cdot 05\end{array}$ & & $\begin{array}{l}3.2 \\
0.9 \\
8(36 \%) \\
0.01\end{array}$ & & $\begin{array}{l}3 \cdot 1 \\
4 \cdot 0 \\
8(36 \%) \\
\text { ns }\end{array}$ & & \\
\hline
\end{tabular}

Means and standard deviations of SEP component amplitude, latency and inter-peak separation in 20 patients with Friedreich's ataxia median nerve stimulation at the wrist. Two patients from the full series of 22 had all potentials absent. The proportion of patients (N/22) in whom a component was identifiable is indicated in each column. The proportion of female patients (41\% in the full series) was slightly greater in the smaller groups with subcortical potentials preserved (up to $67 \%$ ). Also given are the levels of significance for the differences between patients and normals assessed by the Mann-Whitney U-test. Where a given potential was obtained by stimulation on either side the mean value for left and right arm amplitude and latency was incorporated into the overall group mean. *The mean latency of N9 was distorted by one value of $23.4 \mathrm{~ms}$, the remainder having a mean of 9.1 and standard deviation $1.0 \mathrm{~ms}$. 
arm but absent for the other (five cases for N9, two for N13, one for N20). The proportion of patients in whom each potential was bilaterally absent (or unilaterally absent when only one arm was studied with the appropriate epoch) ranged from $9 \%$ for N20 through $50 \%$ for N13, 55\% for N9 to $64 \%$ for N14. Where identifiable, however, each component was below the normal limit of amplitude in at least another $27 \%$ of the total group (N13 $27 \%$, N9 $36 \%$, N20 $41 \%$ ). The peak of N20 was delayed compared with the normal group in all patients except two for whom it could not be identified, whereas the earlier potentials were less often delayed (N9 $10 \%, \mathrm{~N} 1345 \%, \mathrm{~N} 1475 \%$ ). N9, therefore, showed the lowest incidence of delay, in only one case out of ten in whom it could be identified, but the highest incidence of absence or amplitude attenuation, being within normal amplitude limits in only two cases.

Two examples of patient recordings with subcortical potentials present are shown in fig 2 , the montage being identical to that used for the normal record on the left of fig 1 . In the bottom traces N9 is present with normal latency ( 9 and $10 \mathrm{~ms}$ approximately) but very small amplitude (outside the normal range for DW). N13 (maximal in channel 4) is slightly broadened in the left hand recording (DW) but within normal latency limits in each. In both cases, however, the amplitude of N13 is abnormally low. N14 is present but delayed for DW (sharp peak in channel 2) and absent for PB. N20 (channel 1) shows a characteristic prolongation from onset to peak (less well marked for PB), with the peak delayed by more than $10 \mathrm{msec}$ compared with the normal group. The delayed peak of $\mathbf{N 2 0}$ is frequently better seen with a $128 \mathrm{~ms}$ epoch (for example fig 3, upper trace). In fig 3 (IN) the subcortical potentials are absent and the precise onset of $\mathbf{N 2 0}$ is not discernible. Fig 3 also illustrates the abnormal waveform of later cortically-generated potentials, although this simple biphasic configuration was not universal (see, for example, fig 4).

Inter-group comparisons of SEP amplitude, latency and inter-peak separation (including latency values for $\mathbf{N 2 0}$ onset and peak) were made using the Mann-Whitney U-test (table 2). In view of the high incidence of absent potentials it is not surprising that among cases in which each component was present there was a significant $(p<0.02)$ reduction of amplitude for all three potentials studied (N9, N14, N20). Latencies were significantly increased at the $\mathrm{p}<0.01$ confidence level for N14 and for the onset and peak of N20, and at the $p<0.05$ level for N13, but there was no significant group delay of N9 in spite of one patient for whom the latency was grossly prolonged to about $23 \mathrm{~ms}$.

Left median nerve stimulation at wrist

\section{DW Female 54 years}

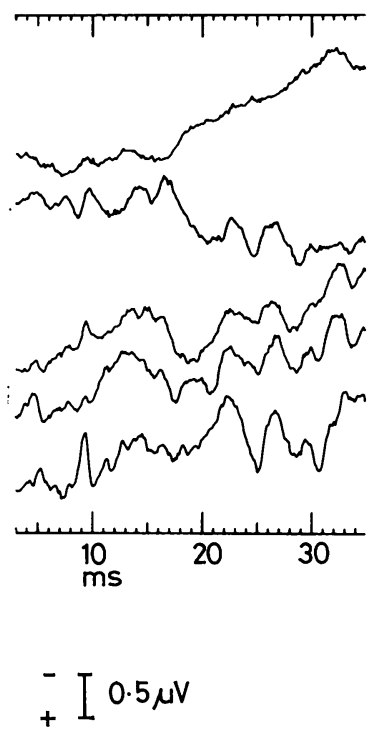

PB Male 36 years

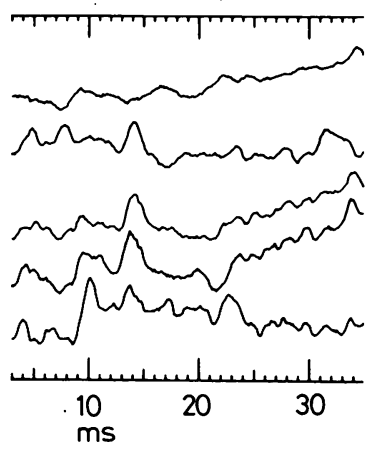

$+[1 \mu \mathrm{V}$

Fig 2 Two examples of short latency somatosensory evoked potentials following median nerve stimulation at the wrist in patients with Friedreich's ataxia (average of 1,200 sweeps). See fig. 1 for identification of components. N9, N13, N14 and N20 are visible on the left (N20 broadened with a peak at $32 \mathrm{~ms})$, and N9, N13 and N20 (peak just visible at $34 \mathrm{~ms}$, confirmed by recording with a longer averager epoch) on the right. 


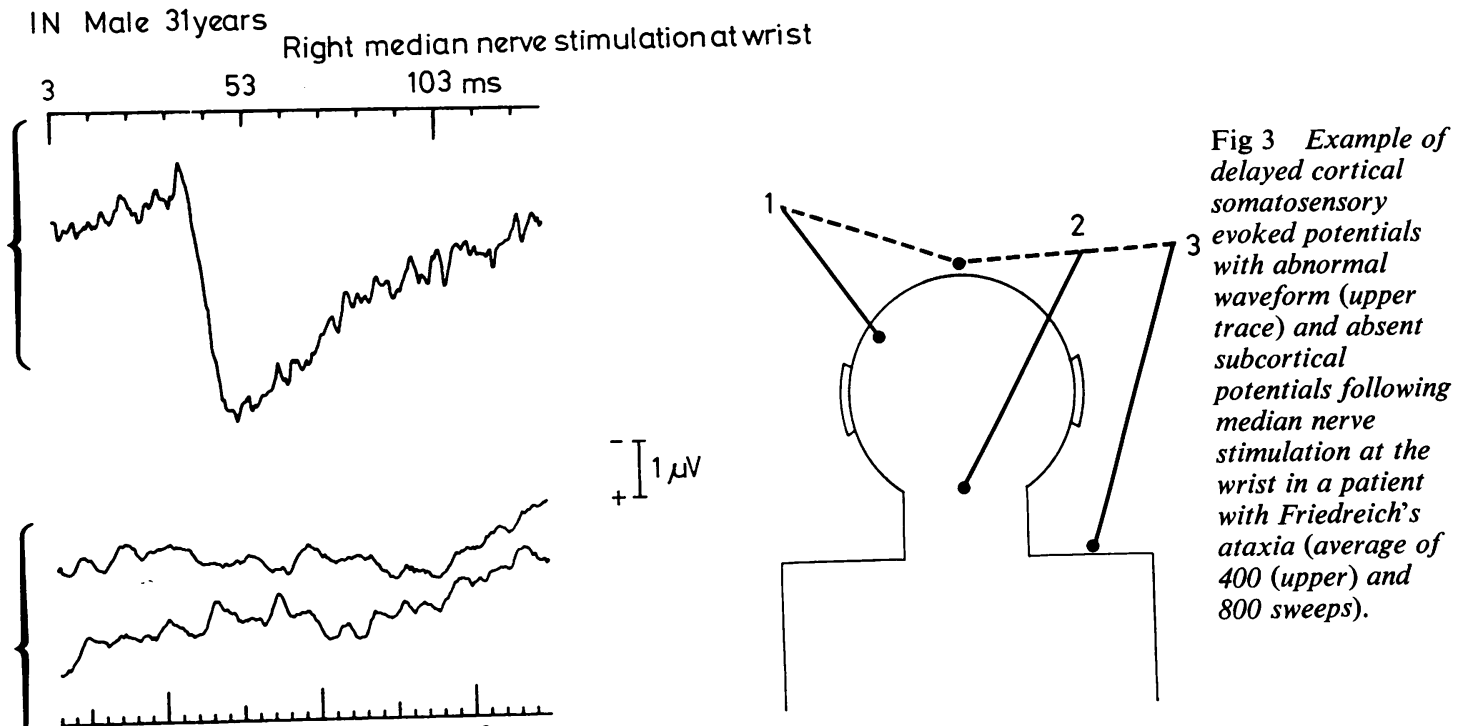

Considering only the patients in whom one or more subcortical potential was identifiable $(n=12)$, N20 was of significantly reduced amplitude in this group also (mean $1.4 \mu \mathrm{V}$, standard deviation $0.6 \mu \mathrm{V})$, and of significantly prolonged onset and peak latency $(20 \cdot 4 \pm 3 \cdot 1$ and $29 \cdot 3 \pm 4 \cdot 8 \mathrm{~ms}$ respectively). There was a higher proportion of males in the patient group (13 out of 22 compared with 3 out of 10), which may have resulted in a slightly greater overall mean latency due to greater mean arm length, ${ }^{8}$ but when the seven females in the normal group were compared with the three males the difference in mean N13 latency was only $1.2 \mathrm{~ms}$ (females $12 \cdot 1$, males $13 \cdot 3 \mathrm{~ms}$ ). This suggests that the higher proportion of males in the patient group might be expected to account for approximately $0.2 \mathrm{~ms}$ out of the $0.9 \mathrm{~ms}$ increase in mean N13 latency, although the former figure is based on a very small sample.

In a between-groups analysis of inter-peak separations (Mann-Whitney U-test, table 2) the patient group showed a significant enhancement in the values for N9-N13, N13-N14 and N20 onset-topeak separation, but the difference in N14-N20 onset was not significant. By far the greatest increase was in N20 onset-to-peak separation $(10.7 \mathrm{~ms}$ compared with $2.5 \mathrm{~ms}$ in normal subjects) while other increases were between 1 and 2 ms. N20 onset-to-peak was also greatly prolonged to a mean of $8.9 \mathrm{~ms}$ in the smaller group with subcortical potentials present.

Cortical SEPs were also recorded from six healthy controls and ten patients with the stimulus delivered to the median nerve at the elbow in the same arm 


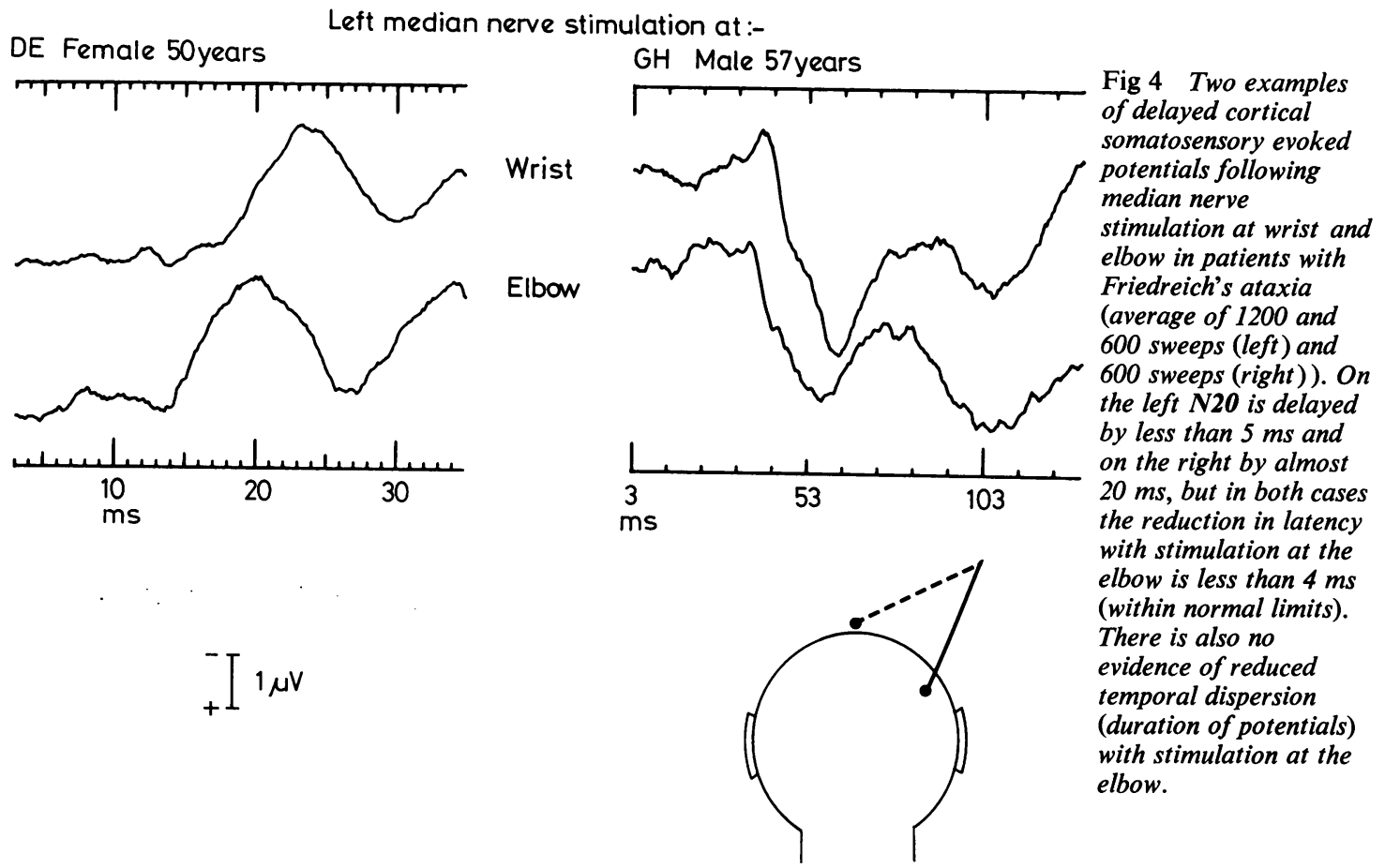

nerve conduction.

2. Reduction in amplitude and frequent absence of the cervical N13 potential with a slight but significant prolongation of peak latency.

3. Frequent absence of the N14 potential (recorded between mastoid and scalp electrodes) which, when identifiable, was more markedly delayed than N13.

4. Gross temporal dispersion and prolonged peak latency of the scalp-recorded $\mathbf{N 2 0}$ potential, which was shown to be mediated by afferent fibres with normal conduction velocity in the forearm. Later components of the cortical SEP waveform were dispersed to a similar degree when the

Table 4 Wrist-elbow conduction time for early cortical SEP Component (N20)

\begin{tabular}{llll}
\hline & & Controls & Patients \\
\hline N20 peak latency & Mean & $3 \cdot 3$ & $3 \cdot 7$ \\
difference between & SD & $0 \cdot 5$ & $1 \cdot 2$ \\
wrist and elbow & $\mathrm{N}$ & 6 & 8 \\
stimulation (ms): & $\mathrm{p}<$ & & $\mathrm{ns}$ \\
\hline
\end{tabular}

Comparison of SEP latency differences (N20 peak latency) with stimulation of the median nerve at the wrist and elbow in the same arm between 6 normal controls ( 4 female) and 8 patients with Friedreich's ataxia ( 2 female). In 2 additional patients the waveforms were insufficiently reliable to derive a latency difference figure. Individual values were compared between groups using the MannWhitney U-test. stimulus was delivered to the elbow instead of the wrist.

In an individual the most common pattern of abnormality was a dispersed and delayed cortical SEP waveform with $(a)$ preceding potentials absent, or (b) N9 of reduced amplitude and normal latency, N11 not identifiable, N13 attenuated but virtually undelayed and N14 (if present) slightly delayed.

\section{Discussion}

Previous electrophysiological findings concerning peripheral sensory nerve conduction in Friedreich's ataxia have on the whole been consistent with an axonal (Wallerian) form of neuropathy, primarily involving large myelinated fibres. There is frequently an absence of sensory action potentials (SAPs) at the wrist following digital nerve stimulation, ${ }^{3-6}$ although a number of cases have been reported with apparently delayed SAPs. ${ }^{3-4-6}$ However, after a more detailed analysis of the compound action potential recorded from the sural nerve in vitro Dyck et $a l^{2}$ reported a marked reduction in the amplitude of the peak attributable to large diameter fibres, but found no evidence of delayed conduction.

The cortical potentials evoked by digital or median nerve stimulation are seldom absent (possibly due to trans-synaptic amplification) but are usually 
delayed, with a broadened waveform suggestive of increased temporal dispersion..$^{11-15}$ In the earliest account $^{11}$ it was not shown whether this was due to a peripheral or a central pathology. In the recordings of Desmedt and Noel, ${ }^{13}$ however, it was shown that the delayed onset of the SEP could not entirely be accounted for by slowed conduction in the peripheral nerve, although the sensory conduction velocity between stimulation sites at the tips of the fingers and the axilla (derived from the difference in N20 onset latency) was somewhat reduced, at $31.5 \mathrm{~m} / \mathrm{s}$. Assuming this velocity to be maintained as far as the spinal cord, it can be deduced that an additional delay of up to 10 ms must have occurred in the central somatosensory pathway to account for the onset of $\mathbf{N 2 0}$ at approximately $38 \mathrm{~ms}$ following stimulation of the fingers. The patient was one in whom no SAPs could be recorded, and the SEPs therefore provided the sole evidence of delayed peripheral and central sensory nerve conduction. In a later investigation Noël and Desmedt ${ }^{13}$ studied the breakdown of $\mathbf{N 2 0}$ into two or more peaks (similar, although not identical, to the onset-peak prolongation noted in the present study) and concluded that the effect, although pronounced, was not related to the peripheral neuropathy and might therefore result from degeneration of the posterior columns.

Two recent accounts describing cortical SEPs recorded in conjunction with subcortical potentials fromthe cervical region ${ }^{14-15}$ also suggest a divergence between central and peripheral sensory conduction defects, first intimated by Noël and Desmedt. ${ }^{13}$ The peripheral conduction time estimated from cervical SEP latency following median nerve stimulation at the wrist was within normal limits or only slightly increased in both studies (although the cervical SEP was frequently of reduced amplitude or absent), but the cortical responses were markedly delayed. These findings have been statistically confirmed by the present study, in which the cortical SEP waveform was found to be markedly delayed and dispersed even in those patients with subcortical SEPs present, the cervical N13 potential was only marginally delayed in the group as a whole, and the peripheral N9 component was delayed in only one patient out of ten. Moreover, in contrast to the findings of Desmedt and Noël, ${ }^{12}$ the N20 peak was found to be mediated by peripheral nerve fibres with normal conduction velocity between stimulation sites at the wrist and the elbow.

The N9 potential has been shown to originate in the brachial plexus distal to the dorsal root ganglia, the evidence being its distribution and properties in normal subjects ${ }^{9}$ and its preservation (with later potentials absent) in patients with traction lesions of the brachial plexus, where the lesion was subsequently shown by surgical exploration to be proximal to the dorsal root ganglia at $\mathrm{C} 6$ and/or $\mathrm{C} 7 .{ }^{16} \mathrm{N13}$ is optimally recorded from the cervical region between the second and seventh vertebrae and, by analogy with a similar negative-going potential recorded from the lower thoracic and lumbar region following stimulation of the lower limb, ${ }^{17} 18$ is thought to reflect pre-synaptic and post-synaptic potentials arising in the dorsal horn. ${ }^{19}{ }^{21}$ It is possible, however, that the positive potential at similar latency to N13 and recorded by the mid-frontal "reference" electrode may be due to activity in the brainstem. ${ }^{22}$ N14, which is almost synchronous with another positive potential (P15) slightly lateralised over the scalp contralateral to the stimulated arm, is thought to arise in the lemniscal pathways of the brainstem. ${ }^{922}{ }^{23}$ There is still some disagreement concerning the origin of $\mathbf{N 2 0}$ but this component is likely to reflect the arrival of the afferent volley in the primary somatosensory cortex. ${ }^{24}$ It has been shown ${ }^{25-27}$ that in patients with dissociated sensory loss due to spinal cord lesions the cortical SEP waveform is abnormal in association with impairment of proprioceptive sensation, but is unaffected when sensory loss in the appropriate limb is confined to the modalities of temperature and pain. This supports the hypothesis, likely on anatomical grounds, that the afferent volley which gives rise to the cortical SEP is conducted in the posterior columns of the spinal cord.

In Friedreich's ataxia, therefore, the major locus of the pathology causing loss of SEP amplitude would appear to be the peripheral nerve (since N9 showed the most marked amplitude reduction) while the delay and dispersion of $\mathbf{N 2 0}$ seems to be a central effect due to degeneration of the posterior columns or higher structures. If the main central involvement of the somatosensory pathway is confined to the posterior columns one might expect N14 to be dispersed and delayed along with $\mathbf{N 2 0}$, but the former is not easily identified when dispersed, and was indeed judged to be absent in a much larger proportion of cases. Although it may be significant that the latency separation between N14 and N20 onset was not statistically enhanced in the patient group, the data do not permit a more precise localisation of the pathology causing delayed central conduction, nor indeed do they provide real evidence to corroborate the proposed generators of $\mathrm{N13}$ and N14.

It is now generally accepted that the neuropathy in Friedreich's ataxia is primarily a form of axonal degeneration. ${ }^{728}$ In this context there are a number of causative factors which might be invoked to account for the delay and dispersion of N20. 
(1) Selective loss of the larger peripheral and central sensory axons mediating the response, resulting in a greater reliance on the surviving smaller fibres whose contribution is obscured in normal individuals. This hypothesis can be virtually ruled out, at least for the peripheral nerve, by the finding of normal conduction velocity between the wrist and elbow in the very fibres which give rise to a delayed cortical response. It is conceivable, however, that the selective loss of large fibres might occur only in the central pathway, where the neuroglial environment is different.

(2) Segmental or paranodal demyelination. Multiple regions of segmental demyelination and remyelination have been observed in fibres of the sural nerve at biopsy, and are thought to be a secondary effect of axonal shrinkage, ${ }^{7}$ but the evidence suggests that this is not associated with slowed conduction. ${ }^{2}$ As with the previous hypothesis, however, it is theoretically possible that the different nature of the myelin sheath surrounding the central axon (supplied by oligodendrocytes and astrocytes rather than by Schwann cells) might result in a different pattern of axonal degeneration with a greater emphasis on demyelination in the early stages.

(3) Shrinkage of large peripheral and central sensory axons, associated with a "dying-back" form of neuropathy. If shrinkage occurs first in the axonal segments furthest from the somata of the dorsal root ganglion cells ${ }^{28}$ then this might result in delayed conduction at the rostral extremity of the posterior columns, while, with the stimulus delivered to the wrist or the elbow, the shrunken segments at the distal end of the peripheral nerve are not involved in mediating the evoked response. Such a mechanism might explain the discrepancy between the present findings and those of Desmedt and Noël, ${ }^{12}$ in which peripheral sensory nerve conduction was found to be slowed when the more distal stimulus was delivered to the distal phalanges of the digits. However, although there is evidence that the loss of large myelinated fibres in Friedreich's ataxia is preceded by a shrinkage in the volume of the axon cylinder, ${ }^{2}{ }^{28}$ there appears to be no evidence that axonal shrinkage gives rise to slowed conduction. In a recent study of acrylamide neuropathy in the cat ${ }^{29}$ it was found that the "dying-back" of large diameter axons was accompanied by an elevation of the electrical activation threshold in the most distal part (5mm approximately) of the fibre which remained excitable, but when excited by a stronger stimulus the axon conducted at the normal velocity. It is not clear, however, how far the findings in acrylamide neuropathy can be extrapolated and applied to the situation in Friedreich's ataxia.

(4) Abnormal synaptic transmission between dor- sal column fibres in the early stages of degeneration and second order neurones in the dorsal column nuclei. Clearly such a process would not effect conduction velocity in the peripheral nerves, although there might be related changes at the distal extremities.

It may be significant that in a parallel study of visual evoked potentials recorded from the same patients $^{30}$ a very similar degree of slowing was encountered, together with a loss of VEP amplitude, and it is tempting to suggest that a common process might be responsible for both VEP and SEP findings. However, in contrast to the present study, there was no evidence of increased temporal dispersion in the occipital response evoked by a pattern reversal stimulus. It is not yet apparent how this difference can be reconciled.

Whatever the underlying mechanism it appears that the pattern of SEP abnormality in Friedreich's ataxia is sufficiently characteristic (even in the youngest patients studied, aged nine and 13 years) to distinguish this condition from; a) peripheral neuropathy (axonal or demyelinating) without CNS involvement, b) degenerative diseases of the CNS without peripheral sensory nerve involvement, and (c) multiple sclerosis. The characteristic SEP features in Friedreich's ataxia are; (1) loss of amplitude of peripheral (N9) and cervical (N13) potentials, without evidence of markedly delayed peripheral nerve condition, (2) dispersed and delayed cortical potentials with a prolongation of $\mathbf{N 2 0}$ inset-to-peak separation, (3) a normal shift in the latency of $\mathbf{N 2 0}$ without evidence of any increase of temporal dispersion, when the stimulus is delivered to the wrist rather than the elbow.

\section{References}

1 Hughes JT, Brownell B, Hewer RL. The peripheral sensory pathway in Friedreich's ataxia. Brain 1968; 91:803-18.

2 Dyck PJ, Lambert EH, Nichols PC. Quantitative measurement of sensation related to compound action potential and number and sizes of myelinated and unmyelinated fibres of sural nerve in health, Friedreich's ataxia, hereditary sensory neuropathy and tables dorsalis. In: Cobb WA, ed. Handbook of Electroencephalography an! Clinical Neurophysiology, volume 9. Amsterdam: Elsevier, 1971: 83-118.

3 McLeod JG. An electrophysiological and pathological study of peripheral nerves in Friedreich's ataxia. J Neurol Sci 1971; 12:333-49.

4 Oh SJ, Halsey JH. Abnormality in nerve potentials in Friedreich's ataxia. Neurology (Minneap) 1973; 23:52-4.

5 Dunn HG. Nerve conduction studies in children with Friedreich's ataxia and ataxia-telangiectasia. 
Dev Med Child Neurol 1973; 15:324-37.

6 Peyronnard JM, Lapointe L, Bouchard JP, Lamontagne A, Lemieux B, Barbeau A. Nerve conduction studies and electromyography in Friedreich's ataxia. Can J Neurol Sci 1976; 3: 313-7.

7 Dyck PJ, Lais AC. Evidence for segmental demyelination secondary to axonal degeneration in Friedreich's ataxia. In: Kakulas BA, ed. Clinical Studies in Myology. Amsterdam: Excerpta Medica, 1973: 253-63.

8 Matthews WB, Beauchamp M, Small DG. Cervical somatosensory evoked responses in man. Nature 1974; 252:230-2.

9 Jones SJ. Short latency potentiales recorded from the neck and scalp following median nerve stimulation in man. Electroencephalogr Clin Neuropinysiol 1977; 43:853-63.

10 Hume AL, Cant BR. Conduction time in central somatosensory pathways in man. Electroencephalogr Clin Neurophysiol 1978; 45:361-75.

11 Bergamini L, Bergamasco B, Fra L, Gandiglio G, Mombelli AM, Mutani R. Réponses corticales et périphériques évoquées par stimulation du nerf Jans la pathologie des cordons postérieurs. $R e v$ Neurol (Paris) 1966; 115:99-112.

12 Desmedt JE, Noël P. Average cerebral evoked potentials in the evaluation of lesions of the sensory nerves and of the central somatosensory pathway. In: Desmedt JE, ed. New Developments in Electromyography and Clinical Neurophysiology, volume 2. Basel: Karger, 1973: 352-71.

13 Noël P, Desmedt JE. The somatosensory pathway in Friedreich's ataxia. Acta Neurol Belg 1976; 76:271.

14 Sauer M, Schenck E. Electrophysiologic investigations in Friedreich's heredoataxia and in hereditary motor and sensory neuropathy. Electroencephalogr Clin Neurophysiol 1977; 43:623.

15 Mastaglia FL, Black JL, Edis R, Collins DWK. The contribution of evoked potentials in the functional assessment of the somatosensory pathway. In: Tyrer JH, Eadie MJ, eds. Clinical and Experimental Neurology (Proc Aust Assoc Neurol), Vol 15. Sydney: Adis Press, 1978: 27998.

16 Jones SJ. Investigation of brachial plexus traction lesions by peripheral and spinal somatosensory evoked potentials. J Neurol Neurosurg Psychiatry 1979; 42:107-16.

17 Delbeke J, McComas AJ, Kopec SJ. Analysis of cvoked lumbosacral potentials in man. $J$ Neurol Neurosurg Psychiatry 1978; 41:293-302.
18 Jones SJ, Small DG. Spinal and subcortical evoked potentials following stimulation of the posterior tibial nerve in man. Electroencephalogr Clin Neurophysiol 1978; 44:299-306.

19 Gasser HS, Graham HT. Potentials recorded in the spinal cord by stimulation of the dorsal roots. Am J Physiol 1933; 103:303-20.

20 Bernhard CG. The spinal cord potentials in leads from the cord dorsum in relation to the peripheral source of afferent stimulation. Acta Physiol Scand 1953; 19: Supplement 106, 1-29.

21 Austin GM, McCouch GP. Presynaptic component of intermediary cord potential. J Neurophysiol 1955; 18:441-51.

22 Arezzo J, Legatt AD, Vaughan HG Jr, Topography and intracranial sources of somatosensory evoked potentials in the monkey. I. Early components. Electroencephalogr Clin Neurophysiol 1979; 46:155-73.

23 Nakanishi T, Shimada Y, Sakuta M, Toyokura Y. The initial positive component of the scalprecorded somatosensory evoked potential in normal subjects and in patients with neurological disorders. Electroencephalogr Clin Neurophysiol 1978; 45:26-34.

24 Goff WR, Allison T, Vaughan HG Jr. The functional neuroanatomy of event related potentials. In: Callaway E, Tueting P, Koslow SH, eds. Event-related brain potentials in man. New York: Academic Press, 1978: 1-79.

25 Halliday AM, Wakefield GS. Cerebral evoked potentials in patients with dissociated sensory loss. J Neurol Neurosurg Psychiatry 1963; 26:211-9.

26 Giblin DR. Somatosensory evoked potentials in healthy subjects and in patients with lesions of the nervous system. Ann NY Acad Sci 1964; 112: 93-142.

27 Fukushima T, Mayanagi Y. Neurophysiological examination (SEP) for the objective diagnosis of spinal lesions. In: Klug W, Brock $\mathbf{M}$, Klüger $\mathbf{M}$, Spoerri $\mathrm{O}$, eds. Advances in Neurosurgery, volume 2. Berlin: Springer, 1975: 158-68.

28 Greenfield JG. The Spinocerebellar Degenerations. Oxford: Blackwell, 1954.

29 Sumner AJ. Physiological studies of toxic neuropathies. Invited contribution to the 6th International Congress of Electromyography, Stockholm, 1979.

30 Carroll WM, Kriss A, Baraitser M, Barrett G, Halliday AM. The incidence and nature of visual pathway involvement in Friedreich's ataxia. Brain 1980; 103:413-34. 